\title{
Sudden-onset asthma exacerbations: clinical features, response to therapy, and 2-week follow-up
}

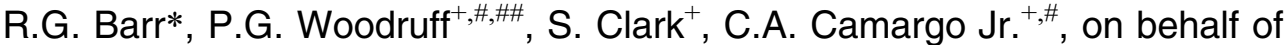 \\ the Multicenter Airway Research Collaboration (MARC) investigators
}

Sudden-onset asthma exacerbations: clinical features, response to therapy, and 2-week follow-up. R.G. Barr, P.G. Woodruff, S. Clark, C.A. Camargo Jr., on behalf of the Multicenter Airway Research Collaboration (MARC) investigators. (C) ERS Journals Ltd 2000. ABSTRACT: Sudden-onset asthma exacerbations may have different triggers and responses to treatment than slower-onset exacerbations. The authors studied this hypothesis among patients with severe asthma exacerbations.

The Multicenter Airway Research Collaboration prospectively enrolled patients presenting to 64 North American emergency departments with asthma exacerbations. Of 1,847 patients aged 18-54 yrs, 900 had severe exacerbations (peak expiratory flow rate (PEFR) $<\mathbf{5 0 \%}$ predicted or hospitalized without PEFR). These patients were divided into sudden-onset ( $\leq 3 \mathrm{~h}$ of symptoms) and slower-onset ( $>3 \mathrm{~h}$ of symptoms) groups.

Fourteen per cent $(95 \%$ confidence interval, 11-16\%) of patients with severe asthma exacerbations had sudden-onset exacerbations. Sudden-onset patients were similar to slower-onset patients, except triggers of their exacerbations were more often respiratory allergens, exercise or psychosocial stress and less often respiratory infections. Sudden-onset patients were more likely to have used oral $\beta$-agonists and salmeterol in the preceding 4 weeks. Although initial PEFRs and management were similar, sudden-onset patients had a greater improvement in PEFR (35 versus $\mathbf{2 8 \%} \mathbf{p}<\mathbf{0 . 0 0 1}$ ). Sudden-onset patients were less often discharged on systemic corticosteroids, but had similar 2 -week relapse rates compared with slower-onset patients.

Among patients presenting with severe asthma exacerbations, sudden-onset exacerbations had a different pattern of triggers and greater improvement with treatment than slower-onset exacerbations.

Eur Respir J 2000; 15: 266-273.

Sudden-onset asthma exacerbations may represent a distinct clinical entity from exacerbations that present with a slower onset of symptoms [1]. Sudden-onset exacerbations have been defined previously by the development of severe airway obstruction within $1.5 \mathrm{~h} \mathrm{[2]}$ or $3 \mathrm{~h}$ of the onset of symptoms [3-5]. A subset of patients with fatal asthma present with sudden-onset symptoms, and patients with severe sudden-onset exacerbations may share characteristics with these patients [5-9].

Prior studies have suggested that sudden-onset asthma exacerbations are less often triggered by respiratory infections and have a faster response to therapy compared with slower-onset exacerbations $[3-5,10]$, however those studies were retrospective and relatively small. In the present study, the authors describe the clinical features, response to therapy, and 2-week follow-up of adults with severe, sudden-onset asthma exacerbations who were prospectively enrolled and followed as part of a large, multicentre cohort.
*General Medicine Division and ${ }^{+}$Dept of Emergency Medicine, Massachusetts General Hospital, Boston, MA, USA. ${ }^{\#}$ Channing Laboratory, Dept of Medicine, Brigham and Women's Hospital, Harvard Medical School, Boston, MA, USA "\#ivision of Pulmonary and Critical Care Medicine, Dept of Medicine, University of California at San Francisco, San Francisco, CA, USA.

Correspondence: R.G. Barr, 50 Staniford Street, 9th Floor, Massachusetts General Hospital, Boston, MA 02114, USA. Fax: 1 6177243544

Keywords: Asthma exacerbation, suddenonset, triggers

Received: June 281999

Accepted after revision October 171999

R.G. Barr is supported by National Research Service Award PE-11001 (Bethesda, MD, USA). P.G. Woodruff was supported by grant HL-07427 and C.A. Camargo Jr. is supported by grant HL-03533, both from the National Institutes of Health (Bethesda, MD, USA). The Multicenter Airway Research Collaboration is supported by unrestricted grants from GlaxoWellcome Inc. (Research Triangle Park, NC, USA) and Monaghan Medical Corporation (Syracuse, NY, USA).

\section{Methods}

This study combined data from four prospective cohort studies performed in October 1996 to December 1996, April 1997 to June 1997, October 1997 to December 1997, and March 1998 to April 1998 as part of the Multicenter Airway Research Collaboration (MARC) [11]. Using a standardized protocol, investigators at 64 emergency departments (ED) in the USA and Canada provided 24-h-a-day coverage for a median of 2 weeks. Inclusion criteria were physician diagnosis of asthma exacerbation, age 18-54 yrs, and the ability to give informed consent. Repeat visits by individual subjects were excluded. Patients with lost medical records $(n=25)$ were excluded because a diagnosis of asthma could not be confirmed. All patients were managed at the discretion of the treating physician. Of 2,496 eligible patients, 1,847 (74\%) patients were enrolled. The institutional review board at each of the 64 participating hospitals approved the 
study, and informed consent was obtained for all participants.

For the present analysis, the cohort was restricted to patients with severe asthma exacerbations. A severe asthma exacerbation was defined according to the National Asthma Education and Prevention Program (NAEPP) criteria [12] as presentation with a peak expiratory flow rate (PEFR) $<50 \%$ of predicted. In addition, patients who were hospitalized for asthma but did not have an initial PEFR measurement were considered to have had a severe exacerbation.

Sudden-onset exacerbations were defined as presentation to the ED within $3 \mathrm{~h}$ of the onset of symptoms; sloweronset exacerbations were defined as presentation after $3 \mathrm{~h}$ of asthma symptoms.

\section{Data collection}

Investigators conducted the ED interview with a standardized questionnaire to assess patients' demographic characteristics, asthma history, and details of the current asthma exacerbation. The interview was distinct from clinical history-taking, and investigators did not participate in clinical decision-making. Data on ED management and disposition were obtained by chart review. Follow-up data were collected by telephone interview 2 weeks later. All forms were reviewed by site investigators before submission to the MARC Coordinating Centre in Boston, MA, USA, where they underwent further review by trained personnel and then double data entry.

Patients' median household incomes were estimated as the median household income of the Zip code of residence [13]. Primary care provider status was assigned on the basis of the following question: "Do you have a primary care provider (such as a family doctor, internist, or nurse practitioner)?" Post-ED treatment failure was assigned to patients who reported "severe symptoms" during the $24 \mathrm{~h}$ preceding the follow-up interview (asthma symptoms "most of the time" or "severe" discomfort and distress due to their asthma) or who stated that their asthma was "about the same" or worse than at the time of their ED presentation.

PEFR was expressed as percentage of patient's predicted value, based on race, age, sex, and height [14]. Changes in PEFR were expressed as the absolute change in percentage of predicted (e.g., an improvement from 40-70\% pred would be expressed as a change of $30 \%$ ).

Patients were asked to list all usual asthma triggers using a standardized list of potential triggers: respiratory infections, environmental allergens (e.g. dust, pets, pollen), tobacco smoke, other environmental factors (e.g. perfumes, paint, pollution, weather changes, cold air), exercise, ingested substances (e.g. aspirin, sulfites, food), reproductive factors, psychological stress, and other factors. Patients were then asked to identify a single trigger of their current asthma exacerbation.

\section{Statistical analysis}

Analyses were performed using STATA 5.0 (StataCorp, College Station, TX, USA) and SAS 6.12 (SAS Institute, Cary, NC, USA). Data are presented as proportions (with $95 \%$ confidence intervals (CI)), means (with SD), or medians (with interquartile range (IQR)). The association between duration of symptoms (sudden onset, $\leq 3 \mathrm{~h}$; slower onset, $>3 \mathrm{~h}$ ) and other factors was examined using Chi-squared test, Student's t-test, and Wilcoxon rank sum test, as appropriate. Clinically relevant variables, such as age and sex, and variables associated with sudden onset at a $p$-value $\leq 0.10$ were evaluated for inclusion in multivariate logistic regression models. Logistic regression was used to model the association between triggers of current exacerbation and sudden-onset exacerbations after adjustment for covariates. Logistic regression was also used to examine the relationship between sudden-onset exacerbation and hospital admissions and relapse. Linear regression was used to model the relationship between sudden-onset exacerbation and change in PEFR. All odds ratios are presented with $95 \%$ CI. All p-values are two-tailed, with $\mathrm{p}<0.05$ considered statistically significant.

\section{Results}

\section{Demographic factors}

Of 1,847 patients enrolled in MARC, 900 patients had severe asthma exacerbations. Of these patients, 125 (14\%, $95 \%$ CI $11-16 \%$ ) had sudden-onset exacerbations. Patients with sudden-onset exacerbations were similar to patients with slower-onset exacerbations with respect to age, sex, and race/ethnicity (table 1). Measures of socioeconomic status were comparable between the two groups.

\section{Chronic asthma severity}

Table 1 also shows that indices of chronic asthma severity were alike for sudden-onset and slower-onset patients. The two groups had similar rates of childhood asthma, hayfever, current smoking and coexistent chronic obstructive pulmonary disease (COPD); they also had similar histories of systemic corticosteroid use, hospitalization and intubation. In the 12 months preceding presentation, the two groups had similar numbers of asthma-related urgent clinic visits, ED visits, and hospitalizations.

In the 4 weeks preceding presentation, proportions using inhaled $\beta$-agonists, inhaled corticosteroids and systemic corticosteroids were virtually the same, however a higher proportion of patients with sudden onset used oral $\beta$ agonists. The sudden-onset group exhibited a trend toward using more salmeterol and less anticholinergics and theophylline.

Usual triggers of exacerbations differed between the two groups. Sudden-onset patients reported that asthma exacerbations were triggered less often by upper respiratory infections and more often by exercise and psychosocial stress compared with patients with slower-onset exacerbations.

\section{Acute triggers and presentation}

Triggers of the current exacerbation also differed by duration of symptoms. The trigger of sudden-onset exacerbations was less often upper respiratory infection and more often respiratory allergens, tobacco smoke, exercise, and psychological stress (table 2). Ingested substances, menstruation, and medication noncompliance were reported infrequently and did not differ by duration of symptoms. 
Table 1. - Demographic and chronic asthma characteristics of patients with severe acute asthma according to duration of symptoms

\begin{tabular}{|c|c|c|c|}
\hline & $\begin{array}{l}\text { Sudden- } \\
\text { onset } \\
\leq 3 \mathrm{~h}\end{array}$ & $\begin{array}{l}\text { Slower- } \\
\text { onset } \\
>3 \mathrm{~h}\end{array}$ & p-value \\
\hline $\mathrm{n}$ & 125 & 775 & \\
\hline \multicolumn{4}{|l|}{ Demographic factors } \\
\hline Age yrs, mean $\pm \mathrm{SD}$ & $34 \pm 10$ & $35 \pm 10$ & 0.32 \\
\hline Female $\%$ & 51 & 59 & 0.12 \\
\hline Race/ethnicity \% & & & 0.41 \\
\hline White & 19 & 22 & \\
\hline African-American & 57 & 51 & \\
\hline Hispanic & 23 & 25 & \\
\hline Other & 1 & 3 & \\
\hline High school graduate \% & 63 & 69 & 0.18 \\
\hline $\begin{array}{l}\text { Estimated household } \\
\text { income US\$, median IQR }\end{array}$ & $\begin{array}{c}30400 \\
(20000- \\
37900)\end{array}$ & $\begin{array}{c}27000 \\
(19000- \\
36900)\end{array}$ & 0.26 \\
\hline Insurance status \% & & & 0.52 \\
\hline Private & 26 & 29 & \\
\hline Medicaid & 34 & 27 & \\
\hline Other public & 11 & 11 & \\
\hline None & 30 & 33 & \\
\hline $\begin{array}{l}\text { Primary care provider } \\
\text { status } \%\end{array}$ & 58 & 65 & 0.14 \\
\hline \multicolumn{4}{|l|}{ Chronic asthma factors } \\
\hline $\begin{array}{l}\text { Childhood diagnosis } \\
\text { of asthma }<18 \text { yrs } \%\end{array}$ & 61 & 58 & 0.50 \\
\hline Hayfever \% & 63 & 59 & 0.41 \\
\hline Current smoker \% & 28 & 32 & 0.34 \\
\hline Coexistent COPD \% & 1 & 2 & 0.49 \\
\hline $\begin{array}{l}\text { Ever taken systemic } \\
\text { steroids for asthma \% }\end{array}$ & 69 & 75 & 0.21 \\
\hline $\begin{array}{l}\text { Ever hospitalized for } \\
\text { asthma \% }\end{array}$ & 66 & 65 & 0.79 \\
\hline $\begin{array}{l}\text { Ever intubated for } \\
\text { asthma \% }\end{array}$ & 21 & 17 & 0.25 \\
\hline $\begin{array}{l}\text { No. of urgent clinic } \\
\text { visits in past year, } \\
\text { median (IQR) }\end{array}$ & $\begin{array}{c}0 \\
(0-2)\end{array}$ & $\begin{array}{c}0 \\
(0-2)\end{array}$ & 0.59 \\
\hline $\begin{array}{l}\text { No. of ED visits in } \\
\text { past year, median (IQR) }\end{array}$ & $\begin{array}{c}3 \\
(1-6)\end{array}$ & $\begin{array}{c}2 \\
(0-5)\end{array}$ & 0.10 \\
\hline $\begin{array}{l}\text { Admitted for asthma in } \\
\text { past year } \%\end{array}$ & 41 & 32 & 0.07 \\
\hline \multicolumn{4}{|c|}{ Use of medication for asthma in preceding 4 weeks $\%$} \\
\hline Inhaled $\beta$-agonist & 87 & 88 & 0.77 \\
\hline Inhaled corticosteroid & 43 & 45 & 0.75 \\
\hline Systemic corticosteroid & 29 & 30 & 0.84 \\
\hline Salmeterol & 13 & 8 & 0.10 \\
\hline Oral $\beta$-agonist & 16 & 10 & 0.03 \\
\hline Anticholinergic & 5 & 9 & 0.09 \\
\hline Theophylline & 10 & 17 & 0.07 \\
\hline \multicolumn{4}{|l|}{ Usual asthma triggers $\%$ * } \\
\hline Upper respiratory infection & 77 & 86 & 0.02 \\
\hline $\begin{array}{l}\text { Respiratory allergens } \\
\text { (dust, pets, pollen, etc.) }\end{array}$ & 78 & 75 & 0.54 \\
\hline Tobacco smoke & 67 & 58 & 0.09 \\
\hline $\begin{array}{l}\text { Environmental factors } \\
\text { (cold, pollution, paint, etc.) }\end{array}$ & 84 & 81 & 0.42 \\
\hline Exercise & 60 & 45 & 0.006 \\
\hline $\begin{array}{l}\text { Ingested substances } \\
\text { (aspirin, sulfites, etc.) }\end{array}$ & 27 & 24 & 0.44 \\
\hline Menstruation & 9 & 7 & 0.39 \\
\hline Psychosocial stress & 68 & 54 & 0.008 \\
\hline
\end{tabular}

IQR: interquartile range; ED: emergency department. *: restricted to patients participating in two cohorts $(n=639)$, respondents were asked to list all that applied.
The presentation of sudden-onset patients was otherwise similar to that of slower-onset patients. Time of presentation, treatment prior to arrival in the ED, and triage vital signs did not differ between the two groups. Mean initial PEFR (\% pred) was severely and equally reduced in both groups.

\section{Multivariate predictors of sudden-onset exacerbation}

In the multivariate analysis, the associations of presenting triggers and sudden-onset exacerbations persisted after adjustment for age, sex, race/ethnicity, education, and insurance status (table 3 ). Respiratory allergens, tobacco smoke, exercise and psychological stress all were significantly more likely to trigger sudden-onset exacerbations than were respiratory infections. Odds ratios did not materially change after adjustment for markers of chronic asthma severity, except for the association of suddenonset exacerbations with tobacco smoke, which was confounded by chronic asthma severity.

In addition, the use of oral $\beta$-agonists and salmeterol in the preceding 4 weeks were associated with sudden-onset exacerbations. The association between salmeterol with sudden-onset exacerbations was negatively confounded by socioeconomic status and demographics, the odds ratio increased from 1.6 (95\% CI 0.9-2.9) to 2.0 (95\% CI 1.13.6) with this adjustment. In contrast, anticholinergics and theophylline were not significantly associated with suddenonset exacerbations in the multivariate model. Disease severity did not change the strength of the associations of oral $\beta$-agonists and salmeterol with sudden-onset exacerbations. Sudden-onset exacerbations were, in fact, negatively associated with a history of steroid use. Adjustment for several other measures of chronic asthma severity, including continuous oral steroid use, number of urgent clinic visits, ED visits, and admissions for asthma in the preceding year, did not change the associations appreciably (data not shown).

\section{Course and treatment response}

Once in the ED, treatments given to patients with sudden-onset and slower-onset exacerbations were statistically similar, although the trends suggested that suddenonset patients required less treatment than slower-onset patients (table 2).

Fewer patients with sudden-onset exacerbations required admission to the hospital ( 26 versus $35 \%$; $\mathrm{p}=0.07$ ), although this difference did not reach statistical significance. This difference did not change appreciably after adjustment for covariates. Among those discharged from the ED, fewer patients with sudden-onset exacerbations were prescribed systemic corticosteroids.

Despite similar treatments, patients with sudden-onset exacerbations had a higher final mean PEFR and a larger absolute change in PEFR than patients with slower-onset exacerbations (table 2). Sudden-onset exacerbations had a $7.5 \%$ greater absolute change in PEFR than slower-onset exacerbations. After adjustment for potential confounders, this difference did not materially change (table 4). 
Table 2. - Acute asthma presentation and emergency department course, according to duration of symptoms

\begin{tabular}{|c|c|c|c|}
\hline & $\begin{array}{l}\text { Sudden- } \\
\text { onset } \\
\leq 3 \mathrm{~h}\end{array}$ & $\begin{array}{l}\text { Slower- } \\
\text { onset } \\
>3 \mathrm{~h}\end{array}$ & p-value \\
\hline $\mathrm{n}$ & 125 & 775 & \\
\hline \multicolumn{3}{|c|}{ Trigger of current exacerbation \%* } & 0.003 \\
\hline Upper respiratory infection & 25 & 40 & \\
\hline $\begin{array}{l}\text { Respiratory allergens } \\
\text { (dust, pets, pollen) }\end{array}$ & 16 & 11 & \\
\hline Tobacco smoke & 4 & 2 & \\
\hline Exercise & 6 & 2 & \\
\hline Psychosocial stress & 12 & 6 & \\
\hline Other $^{\dagger}$ & 38 & 38 & \\
\hline \multicolumn{4}{|l|}{ Presentation } \\
\hline Time of presentation to triage $\%$ & & & 0.59 \\
\hline $00: 00-06: 00$ & 15 & 14 & \\
\hline $06: 00-12: 00$ & 37 & 32 & \\
\hline $12: 00-18: 00$ & 24 & 26 & \\
\hline $18: 00-24: 00$ & 24 & 29 & \\
\hline $\begin{array}{l}\text { No. of inhaled } \beta \text {-agonist puffs } \\
\text { in } 6 \mathrm{~h} \text { prior to arrival to } \\
\text { triage, median (IQR) }\end{array}$ & $\begin{array}{c}4 \\
(0-14)\end{array}$ & $\begin{array}{c}5 \\
(0-12)\end{array}$ & 0.36 \\
\hline $\begin{array}{l}\text { Received other pre-emergency } \\
\text { department treatment } \%\end{array}$ & 12 & 11 & 0.86 \\
\hline $\begin{array}{l}\text { Initial respiratory rate } \\
\left(\text { breaths } \cdot \min ^{-1}\right), \text { mean } \pm S D\end{array}$ & $24 \pm 5$ & $25 \pm 6$ & 0.64 \\
\hline $\begin{array}{l}\text { Initial PEFR (\% predicted), } \\
\text { mean } \pm \text { SD }\end{array}$ & $33 \pm 9$ & $34 \pm 10$ & 0.42 \\
\hline \multicolumn{4}{|l|}{ Emergency department course } \\
\hline $\begin{array}{l}\text { No. of inhaled } \beta \text {-agonists } \\
\text { in first hour, mean } \pm \text { SD }\end{array}$ & $2.0 \pm 1.0$ & $2.0 \pm 0.9$ & 0.72 \\
\hline $\begin{array}{l}\text { Total no. of inhaled } \\
\beta \text {-agonists, mean } \pm \mathrm{SD}\end{array}$ & $3.3 \pm 1.8$ & $3.7 \pm 2.3$ & 0.06 \\
\hline Received steroid treatment \% & 69 & 76 & 0.08 \\
\hline $\begin{array}{l}\text { Received other asthma } \\
\text { treatment } \%\end{array}$ & 30 & 34 & 0.43 \\
\hline $\begin{array}{l}\text { Final PEFR ( } \% \text { predicted }), \\
\text { mean } \pm \mathrm{SD}\end{array}$ & $68 \pm 20$ & $62 \pm 20$ & 0.001 \\
\hline $\begin{array}{l}\text { Change in PEFR } \\
\text { (\% predicted }), \text { mean } \pm \mathrm{SD}\end{array}$ & $35 \pm 19$ & $28 \pm 19$ & $<0.001$ \\
\hline $\begin{array}{l}\text { Length-of-stay (min), } \\
\text { median (IQR) }\end{array}$ & $\begin{array}{c}176 \\
(125-260)\end{array}$ & $\begin{array}{c}194 \\
(132-280)\end{array}$ & 0.09 \\
\hline Admitted to hospital \% & 26 & 35 & 0.07 \\
\hline $\begin{array}{l}\text { Sent home on systemic } \\
\text { corticosteroids } \% \text { \$ }\end{array}$ & 60 & 75 & 0.02 \\
\hline
\end{tabular}

IQR: interquartile range; PEFR: peak expiratory flow rate. *: restricted to patients participating in two cohorts $(n=640)$; respondents were asked to name a single trigger of presenting exacerbation; ${ }^{\dagger}$ : other includes ingested substances, environmental factors (cold, pollution, paint, etc.), menstruation, medication noncompliance, no identifiable or multiple triggers; each nebulizer treatment was counted as equivalent to six "puffs" from a metered-dose inhaler; ${ }^{\text {§ }}$ : restricted to patients sent home from the emergency department $(\mathrm{n}=566)$.

\section{Two-week follow-up events}

Two-week follow-up data were available for 626 patients $(70 \%)$; patients for whom follow-up data were available had comparable mean ages, duration of symptoms and hospitalization rates to patients without follow-up data, but were more frequently female (63 versus $46 \%$; $\mathrm{p}=0.001$ ) and less frequently African-American (49 versus $58 \% ; \mathrm{p}=0.01)$.
Among patients hospitalized for their asthma exacerbation, length of stay was shorter in patients with suddenonset exacerbations (table 5). Among patients sent home from the ED, the risks of relapse and on-going exacerbation (treatment failure) were alike between patients with sudden-onset and slower-onset exacerbations. Risk of relapse and treatment failure remained comparable after adjustment for potential negative confounders (data not shown).

\section{Discussion}

This prospective, multicentre study demonstrates that, in patients with severe asthma exacerbations, sudden-onset exacerbations are more likely to be triggered by respiratory allergens, exercise and psychological stress and less likely to be triggered by upper respiratory infections. In addition, patients with sudden-onset exacerbations demonstrate greater improvement with therapy, with no increase in subsequent risk of relapse or treatment failure.

The percentage of patients with severe asthma who presented with sudden-onset exacerbations in this study matched previously published estimates. In two smaller studies of patients with severe asthma exacerbations who did not require intubation, the percentages with sudden onset were $13 \%$ and $17 \%[4,15]$. Among patients with more severe presentations, the reported per cent with sudden onset has been greater: in series of intubated patients, $7-29 \%$ had sudden onset $[3,5]$, and in surveys of fatal asthma, 15-58\% had sudden onset $[7,16]$.

WoODRUFF et al. [4] retrospectively described suddenonset exacerbations and found that they were less likely to be triggered by respiratory infections ( 17 versus $40 \%$ ) and more likely to have "unknown triggers". The present study prospectively confirmed that respiratory infections were less common triggers of sudden-onset exacerbations (25 versus 40\%), and identified potential unknown triggers as respiratory allergens, psychological stress and exercise. These associations were independent of each other and did not change after adjustment for disease severity. Tobacco smoke was also associated with sudden-onset exacerbations, however this finding was attributable to differences in chronic asthma severity.

The principal prior evidence for the link between respiratory allergens and sudden-onset asthma exacerbations comes from the outbreaks of soybean-associated asthma in Barcelona, Spain [17]. Triggering of suddenonset exacerbations by soybeans is mediated by a specific immunoglobulin $(\mathrm{Ig}) \mathrm{E}$ reaction to at least two allergens on the hull of the soybean [18-20]. Patients with such soy-related asthma had rapid improvement with treatment and had fewer symptoms of asthma and fewer emergency visits for asthma during 2 yrs of follow-up [21]. In the USA, skin-test reactivity and IgE antibodies to the airborne spores of the Alternaria alternata were associated with a 200 -fold increase in the risk of sudden-onset $(<90$ min) respiratory arrest from asthma [22]. The current study was not designed to investigate specific respiratory allergens, but rather shows that respiratory allergens contribute to sudden-onset exacerbations in a general sample of patients presenting with severe asthma to EDs across North America. 
Table 3. - Multivariate predictors of sudden-onset asthma exacerbation

\begin{tabular}{|c|c|c|c|c|c|c|}
\hline \multirow{2}{*}{ Parameters } & \multicolumn{3}{|c|}{ Model 1} & \multicolumn{3}{|c|}{ Model 2} \\
\hline & MOR & $95 \% \mathrm{CI}$ & p-value & MOR & $95 \% \mathrm{CI}$ & p-value \\
\hline \multicolumn{7}{|l|}{ Trigger of current exacerbation } \\
\hline Upper respiratory infection & 1.0 & - & - & 1.0 & - & - \\
\hline Respiratory allergens (dust, pets, pollen, etc.) & 2.7 & $1.3-5.8$ & 0.008 & 2.8 & $1.3-6.0$ & 0.007 \\
\hline Tobacco smoke & 3.8 & $1.1-13$ & 0.04 & 2.6 & $0.6-11$ & 0.18 \\
\hline Exercise & 6.9 & $2.2-22$ & 0.001 & 8.3 & $2.5-28$ & $<0.001$ \\
\hline Psychosocial stress & 4.0 & $1.7-9.4$ & 0.001 & 4.3 & $1.8-10$ & $<0.001$ \\
\hline Other $^{\dagger}$ & 1.6 & $0.9-2.9$ & 0.13 & 1.5 & $0.8-2.8$ & 0.16 \\
\hline Salmeterol during the past 4 weeks & 1.9 & $1.0-3.5$ & 0.05 & 1.9 & $1.0-3.6$ & 0.06 \\
\hline Oral $\beta$-agonist during past 4 weeks & 1.8 & $1.0-3.2$ & 0.05 & 1.9 & $1.1-3.6$ & 0.03 \\
\hline Ever taken systemic steroid medicine for asthma & & & & 0.6 & $0.4-0.9$ & 0.03 \\
\hline Admitted for asthma in past year & & & & 1.5 & $1.0-2.4$ & 0.08 \\
\hline
\end{tabular}

MOR: multivariate odds ratio; CI: confidence interval. ${ }^{\dagger}$ : other includes ingested substances, environmental factors (cold, pollution, paint, etc.), menstruation, medication noncompliance, no identifiable or multiple triggers. Other triggers of asthma are compared to the trigger of "Upper respiratory infection", therefore upper respiratory infection is the reference value for the MOR associated with other triggers (and hence has no confidence interval). Model 1 includes variables listed as "parameters" (trigger, salmeterol and oral $\beta$ agonist), plus age, sex, race, education and insurance status. Model 2 includes variables listed as "parameters" (trigger, salmeterol, oral $\beta$-agonist, systemic steroid ever, and asthma hospital admission in last year), plus age, sex, race, education and insurance status.

There is less literature on the mechanisms that relate psychological stress and exercise to sudden-onset asthma. Psychological stress may cause bronchospasm via mast cell degranulation [23] and cholinergic pathways [24], both of which would be expected to result in a rapid onset of symptoms. Abrupt cessation of exercise induces a fall in forced expiratory volume in one second (FEV1) of up to $50 \%$ in certain subjects within $10-20 \mathrm{~min}$ of the cessation of activity [25]. This phenomenon has been clearly demonstrated experimentally, but has not, to the authors' knowledge, previously been correlated with presentations of sudden-onset exacerbations.

Ingested substances and nonsteroidal anti-inflammatory drugs also have been described as precipitants of suddenonset exacerbations in case series [26]. In the current study, reported ingested substances were too rare to evaluate with respect to sudden-onset exacerbations. This study does, however, suggest that ingested substances are an infrequent cause of severe asthma exacerbations in a relatively large sample of patients presenting with acute asthma.

Table 4. - Multivariate association of sudden-onset asthma exacerbation with absolute change in percentage of predicted peak expiratory flow rate

\begin{tabular}{lccc}
\hline & $\begin{array}{c}\text { Absolute change in } \\
\text { PEFR attributable } \\
\text { to sudden-onset \% }\end{array}$ & $95 \%$ CI & p-value \\
\hline Crude & 7.5 & $3.5-11$ & $<0.001$ \\
$\begin{array}{l}\text { Adjusted for age } \\
\text { Adjusted for age, }\end{array}$ & 7.3 & $3.4-11$ & $<0.001$ \\
$\begin{array}{l}\text { initial PEFR } \\
\text { Fully adjusted }\end{array}$ & 7.1 & $3.2-11$ & $<0.001$ \\
\hline
\end{tabular}

PEFR: peak expiratory flow rate; $\mathrm{CI}$ : confidence interval. *. adjusted for age, initial PEFR, sex, race, education, neighbourhood median household income, insurance status, primary care physician, age at asthma diagnosis, coexistent chronic obstructive pulmonary disease, admission in the preceding year, number of $\beta$-agonists prior to triage, number of $\beta$-agonists given in emergency department and steroid given in emergency department.
Despite identical initial PEFR, patients with suddenonset exacerbations had a $7.5 \%$ greater absolute improvement in PEFR than patients with slower-onset exacerbations. This difference is clinically significant given that patients in this study presented with a mean PEFR of 33\% pred; a 7.5\% absolute increase from this baseline represents a $23 \%$ relative increase in PEFR. The difference was not due to milder exacerbations or earlier presentation in a slower-onset exacerbation of equal severity, since peak flows at triage were identical in sudden-onset and sloweronset patients. Nor was the difference due to differential treatment: sudden-onset patients showed a trend toward requiring fewer $\beta$-agonists treatments and less systemic corticosteroids.

The greater improvement in PEFR carried over to a trend toward less hospitalization in patients with suddenonset exacerbations and a shorter length of stay in those hospitalized. Furthermore, it was not associated with

Table 5. - Follow-up at 2 weeks according to duration of symptoms*

\begin{tabular}{|c|c|c|c|}
\hline & $\begin{array}{c}\text { Sudden- } \\
\text { onset } \\
\leq 3 \mathrm{~h}\end{array}$ & $\begin{array}{c}\text { Slower- } \\
\text { onset } \\
>3 \mathrm{~h}\end{array}$ & p-value \\
\hline $\mathrm{n}$ & 85 & 541 & \\
\hline $\begin{array}{l}\text { Hospital length of stay } \\
\text { (days), median (IQR) }\end{array}$ & $\begin{array}{c}2 \\
(1-3)\end{array}$ & $\begin{array}{c}3 \\
(2-4)\end{array}$ & 0.05 \\
\hline Relapse within $48 \mathrm{~h} \mathrm{\%}^{\dagger}$ & 6 & 3 & 0.19 \\
\hline Relapse within 14 days \% & 13 & 14 & 0.85 \\
\hline Treatment failure $\%$ & 25 & 21 & 0.46 \\
\hline
\end{tabular}

IQR: interquartile range. *: Two week follow-up was available for 626 patients $\left(70 \%\right.$ of cohort); ${ }^{\dagger}$ : relapse event based on patient reporting a "worsening of asthma symptoms" that led to an urgent care visit; ${ }^{*}$ : post-emergency department treatment failure was assigned to patients who reported "severe symptoms" during the $24 \mathrm{~h}$ preceding the follow-up interview (asthma symptoms "most of the time" or "severe" discomfort and distress due to their asthma) or who stated that their asthma was "about the same" or worse than at the time of their emergency department presentation. 
higher rates of treatment failure or relapse over the following 2 weeks. The finding of greater reversibility of airflow obstruction is consistent with prior smaller studies $[3-5,10,15,27]$.

The combination of a distinct pattern of triggers and rapid reversibility suggests that sudden-onset asthma exacerbations may represent a distinct entity as compared to slower-onset asthma exacerbations. Various studies have suggested that sudden-onset exacerbations are immunohistologically distinct from slower-onset exacerbations. Patients who died from sudden-onset exacerbations had fewer eosinophils and more neutrophils in the airway submucosa than patients who died of slower-onset exacerbations [28, 29]. Although lymphocyte numbers, airway wall thickness, areas of smooth muscle and cartilage, and the amount of smooth muscle shortening were similar in these two groups, patients with sudden-onset asthma death had greater mucous gland area than patients with slower-onset asthma death [29]. Such an increase in gland area, with discharge of mucus into the bronchioles, could obstruct airflow if combined with moderate to severe bronchospasm. In addition, patients who died from suddenonset exacerbations appear to have a CD8+ T-cells predominance and an inverted CD4:CD8 ratio, suggesting that sudden-onset exacerbations are not just an exaggeration of the immune response in chronic asthma [30]. Interestingly, this distinct inflammatory reaction occurred regardless of steroid therapy.

The findings of the independent associations of oral $\beta$ agonists and salmeterol with sudden-onset exacerbations were not specified a priori and should be interpreted with caution. They may have resulted from confounding by indication, that is, patients with more severe chronic bronchospasm might have been prescribed more intensive $\beta$-agonist regimens [31]. Salmeterol has been associated with increased ED visits, hospitalizations, and intensive care unit admissions in bivariate analyses, much or all of which has been explained by differences in chronic asthma severity $[32,33]$. Similarly, the association of oral $\beta$-agonists among other medications with death and intensive care unit (ICU) admission has been largely attributed to differences in chronic asthma severity [34].

In the present analysis, patients with sudden-onset exacerbations had similar or milder chronic asthma than patients with slower-onset exacerbations. When the authors adjusted for measures of severity, the strength of the association of salmeterol and oral $\beta$-agonists with suddenonset exacerbations did not change appreciably. In addition to steroid use and recent hospitalization, the authors attempted adjustment with all other available measures of severity and found similar results. The only large doubleblinded randomized trial of salmeterol to measure mortality found a large but statistically insignificant increase in asthma mortality (RR 3.0, 95\% CI 0.7-20) in the salmeterol group [35], however postmarketing surveys have not replicated this result [36]. Further examination of the safety and effectiveness of these drugs in chronic asthma will not come from further observational studies such as this one, but rather would require further clinical trials with follow-up $>4$ months.

This study represents the largest cohort of patients with sudden-onset asthma exacerbations of which the authors are aware, and has other strengths including the prospective collection of patients, enrollment at multiple centres, and good rates of enrollment and follow-up. However, it was not truly population-based and may therefore suffer from selection bias. Nonetheless, since most North American patients with severe asthma exacerbations present to EDs, the results should be applicable to most patients with severe asthma exacerbations. Although data were gathered prospectively, questionnaire items regarding triggers were collected during the exacerbation, and therefore may be subject to recall bias. This could affect the results if recall differed between patients with sudden and slower-onset exacerbations. Also, the best measure of chronic asthma severity, baseline chronic PEFR, was not available. However, there were multiple questionnaire items on chronic asthma severity and none differed between sudden and slower-onset patients.

The definition of a severe asthma exacerbation is somewhat arbitrary. The authors' definition (PEFR $<50 \%$ pred) reflects the most recent NAEPP guidelines. Defining severe exacerbations according to the prior NAEPP guidelines (PEFR $\leq 40 \%$ pred) produced quantitatively similar results, as did the exclusion of patients who were hospitalized without PEFR measurement.

Despite these limitations, this study confirms that severe sudden-onset asthma exacerbations, if treated promptly and aggressively, have similar outcomes as slower-onset exacerbations after discharge from the emergency department. The difference in triggers suggests a difference in aetiology; further work is needed to correlate the epidemiological evidence with pathological distinctions observed thus far. Ultimately, these distinctions may allow identification of patients at risk for sudden-onset "asphyxic" asthma with the goal of prevention and early management.

Acknowledgements. The authors thank F.E. Speizer for support, D.E. Singer for helpful comments on the manuscript, and the MARC investigators for their ongoing dedication to emergency airway research.

Members of the Multicenter Airways Research Collaboration. Steering Committee: J.M. Baren (Children's Hospital of Philadelphia Philadelphia, PA, USA), C.A. Camargo Jr. (Chairman (Massachusetts General Hospital, Boston, MA)), R.K. Cydulka (MetroHealth Medical Center, Cleveland, OH), M.A. Gibbs (Carolinas Medical Center, Charlotte, NC), C.V. Pollack Jr. (Maricopa Medical Center, Phoenix, AZ), B.H. Rowe (University of Alberta Hospital, Edmonton, AB, Canada).

Operations Committee and MARC Coordinating Centre: C.A. Camargo Jr. (Chairman), S. Clark, L.T. Mayer, M.S. Radeos, C.R. Reed, A.K. Singh, R.G. Barr (all Massachusetts General Hospital, Boston, MA, USA).

Principal investigators at the 64 participating sites: F.C. Baker III (Maine Medical Center, Portland, ME, USA), S. Stahmer (Hospital of the University of Pennsylvania, Philadelphia, PA), J.M. Basior (Buffalo General Hospital, Buffalo, NY), C.A. Bethel (Mercy Hospital, Philadelphia, PA), L. Bielory (University Hospital, Newark, NJ), M.P. Blanda (Summa Health System, Akron, OH), D. Bond (Grey Nun's Community Hospital, Edmonton, AB, Canada), G.W. Bota (Sudbury General Hospital, Sudbury, BC, Canada), E.D. Boudreaux (Earl K. Long Memorial Hospital, Baton Rouge, LA), B.E. Brenner (The Brooklyn Hospital Center, Brooklyn, NY), J. Brown (Misericordia Community Hospital, Edmonton, AB, Canada), D.M. Joyce (University Hospital, SUNY HSC, Syracuse, NY), C.A. Camargo Jr. (Massachusetts General Hospital, Boston, MA), F.L. Counselman (Sentara Norfolk General Hospital, Norfolk, VA), G. Ramalanjaona (Newark Beth Israel Hospital, Newark, NJ), R.K. Cydulka (MetroHealth Medical Center, Cleveland, OH), A. Sucov (University of Rochester Hospital, Rochester, NY), D.J. Dire (University of Oklahoma Medical Center, Oklahoma City, OK), N. El Sanadi (Broward General 
Hospital, Ft. Lauderdale, FL, S.D. Emond (St. Luke's/Roosevelt Hospital Center, New York, NY), T.J. Gaeta (Methodist Hospital, Brooklyn, NY and St. Barnabas Hospital, Bronx, NY), M.A. Gibbs (Carolinas Medical Center, Charlotte, NC), T.E. Glynn (Brooke Army Medical Center, Fort Sam Houston, TX), L.G. Graff IV (New Britain General Hospital, New Britain, CT), R.O. Gray (Hennepin County Medical Center, Minneapolis, MN), S.K. Griswold (Thomas Jefferson University Hospital, Philadelphia, PA), A. Guttman (Sir Mortimer B. Davis - Jewish General Hospital, Montreal, QC, Canada), J.P. Hanrahan (Beth Israel Hospital, Boston, MA), F. Harchelroad (Allegheny General Hospital, Pittsburgh, PA), R. Harrigan (Temple University Hospital, Philadelphia, PA), S.E. Hughes (Albany Medical College, Albany, NY), A.H. Idris (University of Florida Health Center, Gainesville, FL), G.D. Innes (St. Paul's Hospital, Vancouver, BC, Canada), M.E. Johnson (Jackson Memorial Hospital, Miami, FL), F.W. Kreplick (Christ Hospital \& Medical Center, Oak Lawn, IL), E.C. Leibner (Detroit Receiving Hospital, Detroit, MI), L.F. Lobon (Beth Israel Medical Center, New York, NY), A. Mangione (Albert Einstein Medical Center, Philadelphia, PA), M.F. McDermott (Cook County Hospital, Chicago, IL), J.S. Mylinski (Richland Memorial Hospital, Columbia, SC), E.S. Nadel (Brigham and Women's Hospital, Boston, MA), R.M. Nowak (Henry Ford Hospital, Detroit, MI), E. Paul (Charity Hospital, New Orleans, LA), C.V. Pollack Jr. (Maricopa Medical Center, Phoenix, AZ), M.S. Radeos (Lincoln Medical Center, Bronx, NY), D.J. Robinson (University of Maryland Medical Center, Baltimore, MD), R.M. Rodriguez (Southwestern Medical Center, Dallas, TX), B.H. Rowe (University of Alberta Hospital, Edmonton, AB, Canada), G. Rudnitsky (Allegheny University - MCP Division, Philadelphia, PA), R.E. Sapien (University of New Mexico Health Sciences Center, Albuquerque, NM), D. Schreiber (Stanford University Medical Center, Stanford, CA), R.A. Silverman (Long Island Jewish Medical Center, New Hyde Park, NY), H. Smithline (Baystate Medical Center, Springfield, MA), D. Stewart (Bronson Medical Center, Kalamazoo, MI), D.M. Taylor (University of Pittsburgh Medical Center, Pittsburgh, PA), C.A. Terregino (Cooper Hospital/ University Medical Center, Camden, NJ), J.L. Larson (University of North Carolina Hospitals, Chapel Hill, NC), A. Walker (Royal Alexandria Hospital, Edmonton, AB, Canada), J. Walter (University of Chicago Hospital, Chicago, IL), E.J. Weber (UCSF Medical Center, San Francisco, CA), L. White (Akron General Medical Center, Akron, $\mathrm{OH})$, J.L. Zimmerman (Ben Taub General Hospital, Houston, TX).

\section{References}

1. Picado C. Classification of severe asthma exacerbations: a proposal. Eur Respir J 1996; 9: 1775-1778.

2. Ferrer A, Torre A, Roca J, Sunyer J, Antó JM, RodriguezRoisin R. Characteristics of patients with soybean dust induced acute severe asthma requiring mechanical ventilation. Am Rev Respir Dis 1990; 142: 429-433.

3. Wasserfallen JB, Schaller MD, Feihl F, Perret CH. Sudden asphyxic asthma: a distinct entity? Am Rev Respir Dis 1990; 142: 108-111.

4. Woodruff PG, Emond SD, Singh AK, Camargo CA Jr. Sudden-onset severe acute asthma: clinical features and response to therapy. Acad Emerg Med 1998; 5: 695701.

5. Kallenbach JM, Frankel AH, Lapinsky SE, et al. Determinants of near fatality in acute severe asthma. Am J Med 1993; 95: 265-272.

6. Molfino NA, Nannini LJ, Martelli AN, Slutsky AS. Respiratory arrest in near-fatal asthma. $N$ Engl J Med 1991; 324: 285-288.

7. Robertson CF, Rubinfeld AR, Bowes G. Deaths from asthma in Victoria: a 12-month survey. Med J Aust 1990; 152: 511-517.

8. Saetta M, Thiene G, Crescioli S, Fabbri LM. Fatal asthma in a young patient with severe bronchial hyperresponsiveness but stable peak flow records. Eur Respir J 1989; 2: 1008-1012.
9. Robin ED, Lewiston N. Unexpected, unexplained sudden death in young asthmatic subjects. Chest 1989; 96: 790793.

10. Jenkins PF, Benfield GFA, Smith AP. Predicting recovery from acute severe asthma. Thorax 1981; 36: 835841.

11. Camargo CA Jr., Woodruff PG. Management of acute asthma in US emergency departments: the Multicenter Asthma Research Collaboration. Am J Respir Crit Care Med 1998; 157: A623.

12. Anonymous. National Asthma Education and Prevention Program. Expert Panel Report 2: guidelines for the diagnosis and management of asthma. Bethesda, MD, USA, National Institutes of Health, 1997.

13. Anonymous. The Sourcebook of Zip code demographics. 12th Edn. Fairfax, VA, USA, CACI Marketing Systems, 1997.

14. Hankinson JL, Odencrantz JR, Fedan KB. Spirometric reference values from a sample of the general US population. Am J Respir Crit Care Med 1999; 159: 179187.

15. Arnold AG, Lane DJ, Zapata E. The speed of onset and severity of acute severe asthma. Br J Dis Chest 1982; 76: 157-163.

16. Sears M, Rea H, Beaglehole R, Gilles A, Holst P, O'Donnell T. Asthma mortality in New Zealand: a two year national study. NZ Med J 1985; 98: 271-275.

17. Antó JM, Sunyer J, Rodriguez-Roisin R, Suarez-Cervera M, Vasquez L, and the Toxicoepidemiology Committee. Community outbreaks of asthma associated with inhalation of soybean dust. N Engl J Med 1989; 320: $1097-$ 1102.

18. Sunyer J, Antó JM, Jose-Rodrigo MJ, Morell F, and the Clinical and Toxicoepidemiology Committee. Casecontrol study of serum immunoglobulin-E antibodies reactive with soybean epidemic asthma. Lancet 1989; i: 179-182.

19. Codina R, Lockey RF, Fernandez-Caldas E, Rama R. Purification and characterization of a soybean hull allergen responsible for the Barcelona asthma outbreaks. II. Purification and sequencing of the Gly $\mathrm{m} 2$ allergen. Clin Exp Allergy 1997; 27: 424-430.

20. Codina RM, Calderon E, Lockey RF, FernandezCaldas E, Rama R. Specific immunoglobulins to soybean hull allergens in soybean asthma. Chest 1997; 111: 75-80.

21. Sabrià $\mathrm{J}$, Antó $\mathrm{JM}$, Sunyer $\mathrm{J}$, et al. Clinical and functional characteristics of patients two years after being affected by the soybean asthma epidemic in Barcelona. Thorax 1994; 49: 906-909.

22. O'Hollaren MT, Yunginger JW, Offord KP, et al. Exposure to an aeroallergen as a possible precipitating factor in respiratory arrest in young patients with asthma. N Engl J Med 1991; 324: 359-363.

23. Pang X, Alexacos N, Letourneau R, et al. A neurotensin receptor antagonist inhibits acute immobilization stressinduced cardiac mast cell degranulation, a corticotropinreleasing hormone-dependent process. J Pharmacol Exp Ther 1998; 287: 307-314.

24. Lehrer PM, Hochron S, Carr R, et al. Behavioral taskinduced bronchodilation in asthma during active and passive tasks: a possible cholinergic link to psychologically induced airway changes. Psychosom Med 1996; 58: 413422.

25. Randolph C. Exercise-induced asthma: update on pathophysiology, clinical diagnosis, and treatment. Curr Probl Pediatr 1997; 27: 53-77. 
26. Picado C, Castillo JA, Montserrat JM, Agusti-Vidal A. Aspirin-intolerance as a precipitating factor of lifethreatening attacks of asthma requiring mechanical ventilation. Eur Respir J 1989; 2: 127-129.

27. Benfield G, Smith A. Predicting rapid and slow response to treatment in acute severe asthma. Br J Dis Chest 1983; 77: 249-254.

28. Sur S, Crotty TB, Kephart GM, et al. Sudden-onset fatal asthma. A distinct entity with few eosinophils and relatively more neutrophils in the airway submucosa. Am Rev Respir Dis 1993; 148: 713-719.

29. Carroll N, Carello S, Cooke C, James A. Airway structure and inflammatory cells in fatal attacks of asthma. Eur Respir J 1996; 9: 709-715.

30. Faul JL, Tormey VJ, Leonard C, et al. Lung immunopathology in cases of sudden asthma death. Eur Respir J 1997; 10: 301-307.

31. Garrett JE, Lanes SF, Kolbe J, Rea HH. Risk of severe life threatening asthma and $\beta$ agonist type: an example of confounding by severity. Thorax 1996; 51: 10931099.

32. Lanes SF, Lanza LL, Wentworth CE III. Risk of emergency care, hospitalization, and ICU stays for acute asthma among recipients of salmeterol. Am J Respir Crit Care Med 1998; 158: 857-861.

33. Williams C, Crossland L, Finnerty J, et al. Case-control study of salmeterol and near-fatal attacks of asthma. Thorax 1998; 53: 7-13.

34. Rea HH, Garrett JE, Lanes SF, Birmann BM, Kolbe J. The association between asthma drugs and severe lifethreatening attacks. Chest 1996; 110: 1446-1451.

35. Castle W, Fuller R, Hall J, Palmer J. Serevent nationwide surveillance study: comparison of salmeterol with salbutamol in asthmatic patients who require regular bronchodilator treatment. BMJ 1993; 306: 1034-1037.

36. Meier CR, Jick H. Drug use and pulmonary death rates in increasingly symptomatic asthma patients in the UK. Thorax 1997; 52: 612-617. 